\title{
Global budgets of organic carbon degradation pathways in marine sediments
}

\author{
DOMINIK HÜLSE ${ }^{1}$, SEBASTIAAN VAN DE VELDE ${ }^{2,3}$, \\ JAMES ANDREW BRADLEY ${ }^{4}$, PHILIP PIKA ${ }^{5}$, ANDY \\ DALE $^{6}$ AND SANDRA ARNDT ${ }^{2}$ \\ ${ }^{1}$ University California Riverside \\ ${ }^{2}$ Université Libre de Bruxelles \\ ${ }^{3}$ Royal Belgian Institute of Natural Sciences \\ ${ }^{4}$ Queen Mary University of London \\ ${ }^{5}$ Vrije Universiteit Amsterdam \\ ${ }^{6}$ GEOMAR Helmholtz Centre for Ocean Research Kiel \\ Presenting Author: dominik.huelse@ucr.edu
}

The microbial degradation of organic carbon $\left(\mathrm{C}_{\mathrm{org}}\right)$ in marine surface sediments is of considerable importance for the global cycling of many chemical elements. While site specific quantifications of $\mathrm{C}_{\text {org }}$ degradation pathways and related processes are possible through the application of diagenetic models, establishing a robust global budget is difficult due to two main reasons: First, complex diagenetic models are computationally too expensive for global-scale applications and upscaling of site specific results is problematic as they are not necessarily representative for a wider seafloor environment. Second, more efficient diagenetic models generally heavily simplify $\mathrm{C}_{\text {org }}$ degradation dynamics and the representation of redox-sensitive elements.

Here, we use an updated analytical diagenetic model as an alternative to establish global budgets of $\mathrm{C}_{\text {org }}$ degradation pathways and fluxes of redox-sensitive elements. The model describes $\mathrm{C}_{\text {org }}$ degradation using a reactive continuum approximation (RCM) and explicitly simulates the associated dynamics of the most important terminal electron acceptors (TEAs, $\mathrm{O}_{2}, \mathrm{NO}_{3}, \mathrm{Fe}^{3+}, \mathrm{SO}_{4}$ ) and reduced substances. The model is driven by seafloor boundary conditions derived from highresolution global maps and compares various approaches to constrain the RCM (e.g. temperature- and redox-dependent approaches). Our spatially variable model results show that sulfate reduction is the main pathway for $\mathrm{C}_{\text {org }}$ degradation in shore, shelf and slope environments while aerobic degradation dominates the sediments of the deep ocean. Furthermore, the model is able to produce realistic fluxes of TEAs and reduced substances and can thus help to improve the representation of biogeochemical exchange fluxes at the sediment-water interface when coupled to an ocean model. However, model results show a significant dependence on the employed RCM, thus highlighting the need for a mechanistic framework to parameterize organic carbon degradation dynamics on a global scale. 